\title{
Characterization of Mono-sex Nile tilapia (Oreochromis niloticus) Hatcheries in Bangladesh
}

\author{
Mekkawy $\mathrm{W}^{1,2 *}$, Barman BK ${ }^{3}$, Kohinoor AHM ${ }^{4}$ and Benzie $\mathrm{JAH}^{1,5}$ \\ ${ }^{1}$ WorldFish, Jalan Batu Maung, Penang, Malaysia \\ ${ }^{2}$ Animal Production Department, Faculty of Agriculture, Ain Shams University, Hadaeq Shubra 11241 Cairo, Egypt \\ ${ }^{3}$ WorldFish, Bangladesh Office, Banani, Dhaka 1213, Bangladesh \\ ${ }^{4}$ Bangladesh Fisheries Research Institute, Mymensingh, 2201, Bangladesh \\ ${ }^{5}$ School of Biological Earth and Environmental Sciences, University College Cork, Cork, Ireland
}

\begin{abstract}
A survey was conducted of the mono-sex tilapia hatcheries in Bangladesh to analyze the structure and management of the hatchery sector in Bangladesh. Eighty-five hatcheries were surveyed by a questionnaire designed to obtain information on owner details, staffing, hatchery production capacity, management processes, and performance for the year 2009, and data from farms supplied by each hatchery. Thirteen quantitative variables were used for a principal component analysis (PCA). Four principal components had eigenvalues greater than 1 , collectively expressing $77.0 \%$ of the total variance with the first two components, $(50.8 \%$ of total variance) reflecting the volume of fry production and available facilities.

Multiple correspondence analysis (MCA) was used to include qualitative variables related to hatchery management and educational level of the owners in the analysis. A two-step cluster analysis using the results of PCA and MCA identified two different groups of hatcheries. One cluster was characterized by high capacity of production of fry, infrastructure and manpower. The other cluster had moderate scales of production. In summary, the management of hatcheries was very similar across Bangladesh with the main difference between them being scale of fry production.
\end{abstract}

Keywords: Mono-sex fry; Nile tilapia; Hatchery survey; GIFT strain; Fry dissemination

\section{Introduction}

Tilapia is the second most commonly cultivated fish species worldwide after the carps. Its reputation for fast growth and ability to grow under wide range of environmental conditions has assisted its adoption in many countries [1]. The global production of tilapia was 4.85 million tonnes in 2014 and is expected to exceed 7 million tonnes by 2030 with Nile tilapia (Oreochromis niloticus) representing more than $70 \%$ of the total production [2].

Following a rapid increase in production of tilapia in Bangladesh over the last decade, Bangladesh became the ninth largest producer of tilapia worldwide in 2012 [2]. Anwar [3] reported a jump of tilapia production in Bangladesh from 33,576 tonnes in 2006-2007 to 66,400 tonnes in 2007-2008. The estimated total production of tilapia in Bangladesh during 2015 was 324,336 tonnes [2]. Nile tilapia culture became popular in Bangladesh after the introduction of the GIFT strain (Genetically Improved Farmed Tilapia) in 1994 [4]. Other strains of Nile tilapia like GenoMar and Chitralada were also introduced subsequently by some private hatcheries [5]. The increased production of Nile tilapia in Bangladesh was accompanied by a dramatic expansion of the number of tilapia hatcheries. Anwar [3] reported that the number of monosex tilapia hatcheries in Bangladesh increased from five in 1999 to 62 in 2007 and 191 in 2010. Almost all commercial tilapia hatcheries in Bangladesh produce mono-sex (all male) fry, and mixed-sex fry are not available on a commercial basis [6]. The advantages of using mono-sex fry are the higher growth rate of the males compared to females and the avoidance of undesired reproduction in the culture system which can negatively affect total production at harvest [7].

Published information on tilapia hatcheries and how they operate in Bangladesh is limited. The objectives of the current study were: 1) to survey the fry production systems from mono-sex tilapia hatcheries and
2) analyze these in relation to capacity of production, management and performance in order to describe the structure of the tilapia hatchery sector in Bangladesh in 2009.

\section{Materials and Methods}

\section{Data collection}

A questionnaire was designed to obtain information on the owner, staff, general hatchery information, capacity of production, management processes, hatchery performance and some information, supplied by the hatchery, on aspects of performance of the farms they supplied (Table 1). Eighty-five hatcheries agreed to participate in the study, $45 \%$ of the total number of hatcheries reported by Anwar [3] and covering all but one region of Bangladesh (Table 2). Personal interviews by researchers from Bangladesh Fisheries Research Institute (BFRI) of hatcheries owners or their representatives were undertaken during May 2010 to October 2011, focusing on collecting data for the production year 2009 (from February until July).

\section{Statistical analysis}

A preliminary correlation analysis between the quantitative variables in Table 1 was carried out to investigate the correlation patterns between

*Corresponding author: Wagdy Mekkawy, WorldFish, Jalan Batu Maung Penang, Malaysia, Tel: +6011-26444846; Fax: +604-626 5530; E-mail: W.Mekkawy@Cgiar.org

Received June 06, 2017; Accepted August 22, 2017; Published August 24, 2017

Citation: Mekkawy W, Barman BK, Kohinoor AHM, Benzie JAH (2017) Characterization of Mono-sex Nile tilapia (Oreochromis niloticus) Hatcheries in Bangladesh. J Aquac Res Development 8: 498. doi: 10.4172/2155-9546.1000498

Copyright: () 2017 Mekkawy W, et al. This is an open-access article distributed under the terms of the Creative Commons Attribution License, which permits unrestricted use, distribution, and reproduction in any medium, provided the original author and source are credited. 
Citation: Mekkawy W, Barman BK, Kohinoor AHM, Benzie JAH (2017) Characterization of Mono-sex Nile tilapia (Oreochromis niloticus) Hatcheries in Bangladesh. J Aquac Res Development 8: 498. doi: 10.4172/2155-9546.1000498

Page 2 of 5

these variables to choose the appropriate variables to include in the principal components analysis (PCA) [8]. The total production of fry and total annual income in 2009, were highly correlated $(>0.9)$ with the production capacity of fry. Both were dropped from the PCA as they were adequately represented by production capacity. Also, each of these two variables had missing data from one or two sites. The age of the owner, number of eggs per spawning, hatching rate and survival rate from hatching to stocking were excluded from PCA because they had very low and non-significant correlations $(<0.3)$ with the other variables [8]. The mating ratio and frequency of brood stock replenishment were omitted from the PCA because these variables had no variation between hatcheries. The data related to the performance of farms supplied by hatchery were also excluded from PCA analysis as

\begin{tabular}{|c|c|}
\hline Sections & Variables \\
\hline \multirow{4}{*}{ Owner details } & Name \\
\hline & Sex \\
\hline & Age \\
\hline & Educational level' \\
\hline \multirow{3}{*}{ Staff information } & Total number of technicians" \\
\hline & Total number of casual workers" \\
\hline & $\begin{array}{c}\text { Total number of attended trainings/workshops/ } \\
\text { seminars" }\end{array}$ \\
\hline \multirow{18}{*}{$\begin{array}{l}\text { General hatchery general } \\
\text { information, capacity of } \\
\text { production and management }\end{array}$} & Name of the hatchery \\
\hline & Location' \\
\hline & Number of years since hatchery establishment" \\
\hline & Total area (hectare)" \\
\hline & Number of ponds for the brood stocks' \\
\hline & Number of ponds for the nursery" \\
\hline & Number of ponds for culture"l \\
\hline & Number of breeding hapas" \\
\hline & Production capacity of fry (million/year)" \\
\hline & Strain of tilapia cultured' \\
\hline & Source of water ${ }^{1}$ \\
\hline & Starting month for production of fry \\
\hline & Peak month for production of fry \\
\hline & Spawning method' \\
\hline & Mating ratio (Male : Female) \\
\hline & Frequency of brood stock replenishment \\
\hline & Feed sourcel \\
\hline & Type of technical support' \\
\hline \multirow{8}{*}{ Hatchery performance } & Total production in 2009 (million fry) \\
\hline & Total annual income (Lakh*) \\
\hline & Average weight of males $(g)^{\prime}$ \\
\hline & Average weight of females $(\mathrm{g})^{\prime}$ \\
\hline & $\begin{array}{l}\text { Average number of eggs (egg/female/spawning) } \\
\text { Average hatching rate during nursing }(\%)\end{array}$ \\
\hline & $\begin{array}{c}\text { Average fry survival rate from hatching until } \\
\text { stocking }(\%)\end{array}$ \\
\hline & Disease problems ${ }^{\prime}$ \\
\hline & $\begin{array}{c}\text { Number of commercial farms served by the } \\
\text { hatchery" }\end{array}$ \\
\hline \multirow{6}{*}{$\begin{array}{l}\text { Performance of farms } \\
\text { supplied by hatchery }\end{array}$} & Average survival during grow-out period (\%) \\
\hline & Average growth period (months) \\
\hline & Average yield per hectare (tonnes) \\
\hline & Average feed consumption per hectare (tonnes) \\
\hline & Average input cost per hectare $\left(\right.$ Lakh $\left.^{* *}\right)$ \\
\hline & Average farm gate price (Taka/kg) \\
\hline
\end{tabular}

' Variables used in multiple correspondence analysis (MCA); "Variables used in the principal component analysis (PCA); ${ }^{* *}$ Lakh $=100,000$ Taka.

Table 1: The questionnaire used in the current study divided into 5 sections reflecting questions related to particular component.

\begin{tabular}{|c|c|c|c|c|}
\hline Divisions & Districts & $\begin{array}{c}\text { Total } \\
\text { number of } \\
\text { hatcheries }\end{array}$ & $\begin{array}{c}\text { Number of hatcheries in } \\
\text { the study }\end{array}$ & $\begin{array}{c}\% \text { of } \\
\text { hatcheries } \\
\text { surveyed }\end{array}$ \\
\hline \multirow{3}{*}{ Barisal } & Barisal & \multirow{3}{*}{5} & 1 & \multirow{3}{*}{60} \\
\hline & \multirow{2}{*}{ Patuakhali } & & 2 & \\
\hline & & & Total $=3$ & \\
\hline \multirow{7}{*}{ Chittagong } & Brhambaria & \multirow{7}{*}{78} & 1 & \multirow{7}{*}{45} \\
\hline & Chandpur & & 8 & \\
\hline & Comilla & & 17 & \\
\hline & Cox's Bazer & & 4 & \\
\hline & Feni & & 2 & \\
\hline & \multirow{2}{*}{ Noakhali } & & 3 & \\
\hline & & & Total $=35$ & \\
\hline \multirow{5}{*}{ Dhaka } & Faridpur & \multirow{5}{*}{69} & 2 & \multirow{5}{*}{35} \\
\hline & Gazipur & & 2 & \\
\hline & Jamalpur & & 1 & \\
\hline & \multirow{2}{*}{ Mymensingh } & & 19 & \\
\hline & & & Total=24 & \\
\hline \multirow{4}{*}{ Khulna } & & \multirow{4}{*}{24} & 10 & \multirow{4}{*}{75} \\
\hline & Jessore & & 7 & \\
\hline & Satkhira & & 1 & \\
\hline & Tangail & & Total $=18$ & \\
\hline \multirow{3}{*}{$\begin{array}{c}\text { Rajshahi \& } \\
\text { Rangpur }\end{array}$} & Pabna & \multirow{3}{*}{13} & 4 & \multirow{3}{*}{38} \\
\hline & Dinajpur & & 1 & \\
\hline & & & Total $=5$ & \\
\hline \multirow{2}{*}{ Sylhet } & \multirow[b]{2}{*}{--} & \multirow[b]{2}{*}{2} & 0 & \multirow[b]{2}{*}{0} \\
\hline & & & Total $=0$ & \\
\hline Total & -- & 191 & 85 & 45 \\
\hline
\end{tabular}

Table 2: The distribution of the mono-sex tilapia hatcheries in Bangladesh according to Anwar (2011) and of the hatcheries used in the study (per division per district) in 2010 .

they were not related to the specific performance of the hatchery. PCA analysis on the remaining 13 variables (Table 1) was used with Varimax rotation method to reduce the dimension of the studied variables into fewer hypothetical variables that explain most of the variation in the data, retaining only principal components with eigenvalues higher than 1 [9].

In order to utilize the qualitative information collected in the survey, multiple correspondence analysis (MCA) using the qualitative variables indicated in Table 2 was performed to obtain the coordinates of the hatcheries on the principal components of MCA [10].

The coordinates of retained principal components from PCA and the coordinates of MCA were used in a two steps cluster analysis (CA) to classify the hatcheries into homogenous groups. After the optimal number of clusters was obtained, using Average Silhouette Width (ASW) [11], the hatcheries were grouped into different clusters in a second step using the K-means method. Analyses of variance (ANOVA) were carried out to test the difference between clusters for the original quantitative variables in the questionnaire. Contingency tables were used to check the different patterns of the distributions of the qualitative variables across clusters. The software SPSS [12] was used to carry out all statistical analyses.

\section{Results}

The survey included 85 of the 191 hatcheries recorded in Bangladesh in 2009/2010 ( $45 \%$ of the total). There were hatcheries from all regions except one (Table 2). Therefore, the results of the survey should provide a sound basis for describing the structure of the hatchery sector.

\section{Descriptive statistics}

The general characteristics and descriptive statistics summarizing 
the variables assessed by the questionnaire are detailed in the following sections.

Owner details: All owners of the hatcheries were males. Their age ranged from 22 to 80 years. The ages of the majority of them (67\%) were between 35 and 50 years. All owners had at least a secondary school education and up to a master degree. Around $53 \%$ of the owners had a bachelor or master degree.

Staff information: Most of the hatcheries (89.41\%) had only one technician and the average production of fry from these hatcheries in 2009 was 8.8 million fries. The rest of the hatcheries had two or three technicians and the average production of fry from these hatcheries in 2009 was 23.8 million fries. The number of casual workers was highly correlated with the annual production of fry in 2009 ( $\mathrm{r}=0.79)$. The staff, including technicians and casual workers of most hatcheries had attended at least to one training course, workshop or seminar related to management of tilapia hatcheries. These events were mostly organized by BFRI. Only staff from $7.06 \%$ of the hatcheries had not attended any such events.

Hatchery general information, capacity of production and management: The hatcheries in the current study were established between 2002 and 2009, with an increasing number of new hatcheries established over time. For example, only one new hatchery was established in each of 2002 and 2003 while a peak of 21 new hatcheries was seen in 2009 .

The total area of individual hatcheries ranged from 1.21 to 20.23 hectares $($ mean $=4.57$, Standard error $[\mathrm{SE}]=0.34$ ). The capacity of fry

\begin{tabular}{|c|c|c|c|}
\hline Variables & Mean & SE & CV \% \\
\hline Total production in 2009 (million fry) & 10.27 & 1.23 & 108.45 \\
\hline Total annual income (Lakh $\left.{ }^{*}\right)$ & 70.07 & 10.30 & 134.32 \\
\hline Average weight of males at harvest (g) & 242.94 & 3.96 & 15.03 \\
\hline Average weight of females at harvest (g) & 207.06 & 3.75 & 16.70 \\
\hline Average number of eggs (egg/female/spawning) & 450.88 & 9.03 & 18.46 \\
\hline Average hatching rate (\%) & 86.04 & 0.63 & 6.75 \\
\hline $\begin{array}{c}\text { Average fry survival rate from hatching until } \\
\text { stocking (\%) }\end{array}$ & 85.88 & 0.60 & 6.44 \\
\hline $\begin{array}{c}\text { Number of commercial farms served by the } \\
\text { hatchery }\end{array}$ & 175.98 & 13.16 & 68.94 \\
\hline *Lakh=100,000 Taka & & & \\
\hline
\end{tabular}

Table 3: The descriptive statistics (mean, standard error (SE) and coefficient of variation $(\mathrm{CV})$ ) of the quantitative variables associated with hatchery performance.

\begin{tabular}{|c|c|c|c|}
\hline Variables & Mean & SE & CV \% \\
\hline Average survival during grow-out period (\%) & 84.89 & 0.31 & 3.37 \\
\hline Average growth period (months) & 4.94 & 0.05 & 9.33 \\
\hline Average yield per hectare (tonnes) & 10.71 & 0.22 & 18.94 \\
\hline Average feed consumption per hectare (tonnes) & 16.64 & 0.33 & 18.28 \\
\hline Average input cost per hectare (Lakh $\left.{ }^{*}\right)$ & 3.89 & 0.10 & 23.70 \\
\hline Average farm gate price (Taka/kg) & 95.59 & 0.67 & 6.46 \\
\hline
\end{tabular}

*Lakh $=100,000$ Taka

Table 4: The descriptive statistics (mean, standard error (SE) and coefficient of variation $(\mathrm{CV})$ ) of the performance of the farms supplied by the hatchery.

\begin{tabular}{|c|c|c|c|}
\hline Component & Eigenvalue & \% of variance & Cumulative \% of variance \\
\hline PC1 & 3.89 & 29.91 & 29.91 \\
\hline PC2 & 2.72 & 20.91 & 50.82 \\
\hline PC3 & 1.89 & 14.51 & 65.33 \\
\hline PC4 & 1.52 & 11.71 & 77.04 \\
\hline
\end{tabular}

Table 5: Eigenvalues of the 4 principal components (PC) after rotation and their associated variances. production was variable and ranged from 1 to 150 million fries per year $($ mean $=15.03, \mathrm{SE}=2.10)$. The production season of the fry started in February and March and reached peak production in April and May. The majority of hatcheries used only commercial feeds for feeding fish and ground water from deep tube wells as a source of water. The number of breeding hapas was highly correlated $(r=0.87)$ with the capacity production of fry. The production capacity of fry had much lower correlations with the number of hatchery ponds, ranging from 0.20 with the number of nursery ponds to 0.44 with the number of brood stock ponds. Seventy five percent of the hatcheries used only hapas for spawning and 25\% used both hapas and ponds for spawning. Most of the hatcheries (75.29\%) used GIFT strain as the only source of the brood stock, $15.29 \%$ used GIFT strain along with other commercial strains, Chitralada or GenoMar, and $9.42 \%$ used Chitralada or GenoMar only as brood stock. All hatcheries had received technical support from BFRI, mostly verbal, although $18.82 \%$ of these hatcheries had also received leaflets as a form of technical support.

Hatchery performance: The descriptive statistics of the quantitative variables associated with hatchery performance are presented in Table 3. The total production of fry in 2009 , total annual income and number of commercial farms served by the hatchery were highly variable (CVs ranging from $69-134 \%$ ). Disease problems were not reported in most of the hatcheries $(87.06 \%)$ but eight hatcheries reported Streptococcus infections, two reported tail and fin rot, and one hatchery reported a parasitic whirling disease.

Performance of farms supplied by the hatchery: The descriptive statistics of the quantitative variables associated with the performance of farms supplied by the hatcheries are presented in Table 4 . The average growth period was around 5 months. The total production per hectare was 10.71 tonnes on average with 1.55 feed conversion rates which provide average revenue of 10.24 Lakh per hectare. The input cost per hectare was 3.89 Lakh; however, this number does not include labor cost or the cost of renting the ponds.

\section{Principal component analysis}

Both the Kaiser-Meyer-Olkin (KMO) statistics, KMO =0.77 [13], and Bartlett's test of sphericity $\left(\chi^{2}=995.9, \mathrm{p}<0.001\right)$ confirmed the correlations between the 13 chosen variables were sufficiently large for the principal component analysis. Four principal components had eigenvalues greater than 1 , collectively expressing $77.04 \%$ of the total variance (Table 5).

The first two principal components were determined by the capacity of production of fry and the needed infrastructure and manpower for this production (Table 6). These two components account for $50.82 \%$ of the total variance. The third component is determined by the body weights of the brood stock used for fry production. The fourth component was characterized by the number of trainings attended, time since the establishment of the hatchery and the number of commercial farms served by the hatchery, three variables potentially linked to the knowledge and experience of the staff and reputation of the hatchery.

\section{Cluster analysis}

The average Silhouette Width (ASW) [11], calculated to determine the optimum number of clusters, was highest $(0.59)$ for the two clusters case, indicating two clusters to be the best description of the data. Table 7 shows the number of hatcheries in each clusters (n), mean, standard error of the quantitative variables across the two different clusters.

A spatial representation of the hatcheries in the two different 
clusters based on the first three principal components is shown in Figure 1. The main differences between the two clusters were in the scale of production of fry, the available facilities and manpower for that production and total annual income (Table 7). Hatcheries in Cluster 2 had greater size and capacity of production than those in Cluster 1. Three of the 75 hatcheries in Cluster 1 had no production records for 2009 , but the 72 which have produced a total of 569.70 million fry in 2009, whereas the ten hatcheries in Cluster 2 produced 272.0 million fries during the same period. The brood stocks at the hatcheries in Cluster 2 were relatively heavier than the brood stocks at the hatcheries

\begin{tabular}{|c|c|c|c|c|}
\hline Variables & PC1 & PC2 & PC3 & PC4 \\
\hline Total number of technicians & 0.706 & 0.222 & -0.003 & -0.365 \\
\hline Total number of casual workers & 0.835 & 0.267 & 0.104 & 0.210 \\
\hline $\begin{array}{l}\text { Total number of attended trainings/ } \\
\text { workshops/seminars }\end{array}$ & 0.049 & 0.117 & 0.014 & 0.870 \\
\hline $\begin{array}{l}\text { Number of years since hatchery } \\
\text { establishment }\end{array}$ & 0.380 & 0.262 & 0.054 & 0.453 \\
\hline Total area (hectare) & 0.301 & 0.871 & 0.062 & 0.141 \\
\hline Number of ponds for the brood stocks & 0.562 & 0.518 & 0.090 & -0.012 \\
\hline Number of ponds for the nursery & 0.159 & 0.783 & 0.288 & 0.210 \\
\hline Number of ponds for culture & 0.082 & 0.892 & -0.002 & 0.021 \\
\hline Number of breeding hapas & 0.876 & 0.173 & 0.166 & 0.205 \\
\hline Production capacity of fry (million/year) & 0.919 & 0.084 & 0.113 & 0.123 \\
\hline Average weight of males (g) & 0.136 & 0.199 & 0.910 & 0.037 \\
\hline Average weight of females (g) & 0.132 & 0.031 & 0.925 & 0.044 \\
\hline $\begin{array}{l}\text { Number of commercial farms served by } \\
\text { the hatchery }\end{array}$ & 0.677 & 0.047 & 0.231 & 0.509 \\
\hline
\end{tabular}

Table 6: Eigenvector weight of the 4 principal components for the variables used in the principal component analysis.

\begin{tabular}{|c|c|c|}
\hline Variables & $\underset{n=75}{\text { Cluster } 1}$ & $\begin{array}{c}\text { Cluster } 2 \\
n=10\end{array}$ \\
\hline Total number of technicians & $1.04^{\mathrm{a}} \pm 0.02$ & $1.80^{\mathrm{b}} \pm 0.25$ \\
\hline Total number of casual workers & $13.09^{\mathrm{a}} \pm 1.00$ & $40.20^{\mathrm{b}} \pm 5.88$ \\
\hline $\begin{array}{l}\text { Number of years since hatchery } \\
\text { establishment }\end{array}$ & $3.69^{a} \pm 0.18$ & $5.20^{\mathrm{b}} \pm 0.61$ \\
\hline Total area (hectare) & $3.81^{a} \pm 0.24$ & $10.32^{\mathrm{b}} \pm 1.3$ \\
\hline Number of ponds for the brood stocks & $3.65^{a} \pm 0.18$ & $7.80^{\mathrm{b}} \pm 0.65$ \\
\hline Number of ponds for the nursery & $3.88^{a} \pm 0.22$ & $9.40^{b} \pm 1.60$ \\
\hline Number of ponds for culture & $3.39^{\mathrm{a}} \pm 0.23$ & $12.40^{\mathrm{b}} \pm 3.32$ \\
\hline Number of breeding hapas & $70.76^{a} \pm 6.41$ & $249.00^{\mathrm{b}} \pm 42.57$ \\
\hline Production capacity of fry (million/year) & $10.80^{\mathrm{a}} \pm 1.06$ & $46.70^{b} \pm 12.57$ \\
\hline Total production in 2009 (million fry) & $7.91^{\mathrm{a}} \pm 0.85$ & $27.20^{\mathrm{b}} \pm 5.82$ \\
\hline Total annual income (Lakh*) & $53.30^{\mathrm{a}} \pm 5.90$ & $201.50^{\mathrm{b}} \pm 63.60$ \\
\hline Average weight of males $(\mathrm{g})$ & $239.13^{a} \pm 4.16$ & $271.50^{\mathrm{b}} \pm 8.73$ \\
\hline $\begin{array}{l}\text { Number of commercial farms served by the } \\
\text { hatchery }\end{array}$ & $157.44^{\mathrm{a}} \pm 11.98$ & $315.00^{\mathrm{b}} \pm 49.47$ \\
\hline Age of owner & $41.84^{\mathrm{a}} \pm 1.20$ & $45.50^{\mathrm{a}} \pm 2.99$ \\
\hline $\begin{array}{l}\text { Total number of attended trainings/ } \\
\text { workshops/seminars }\end{array}$ & $1.83^{\mathrm{a}} \pm 0.13$ & $1.80^{\mathrm{a}} \pm 0.33$ \\
\hline Average weight of females (g) & $205.20^{\mathrm{a}} \pm 4.09$ & $221.00^{\mathrm{a}} \pm 7.59$ \\
\hline $\begin{array}{c}\text { Average number of eggs (egg/female/ } \\
\text { spawning) }\end{array}$ & $452.00^{\mathrm{a}} \pm 10.03$ & $442.50^{\mathrm{a}} \pm 15.83$ \\
\hline Average hatching rate $(\%)$ & $85.97^{a} \pm 0.66$ & $86.50^{\mathrm{a}} \pm 2.11$ \\
\hline $\begin{array}{l}\text { Average fry survival rate from hatching until } \\
\text { stocking }(\%)\end{array}$ & $86.11^{a} \pm 0.53$ & $84.20^{\mathrm{a}} \pm 3.21$ \\
\hline \multicolumn{3}{|c|}{$\begin{array}{l}\text { *Lakh=100,000 Taka; Means with different superscript letters on the same row are } \\
\text { significantly different. }\end{array}$} \\
\hline \multicolumn{3}{|c|}{$\begin{array}{l}\text { Table 7: The numbers of hatcheries in each cluster }(n) \text { and mean } \pm \text { standard error } \\
\text { of the studied variables associated with hatchery performance for the differen } \\
\text { clusters. The upper group of variables are significantly different between clusters } \\
\text { the lower group of variables are not. }\end{array}$} \\
\hline
\end{tabular}

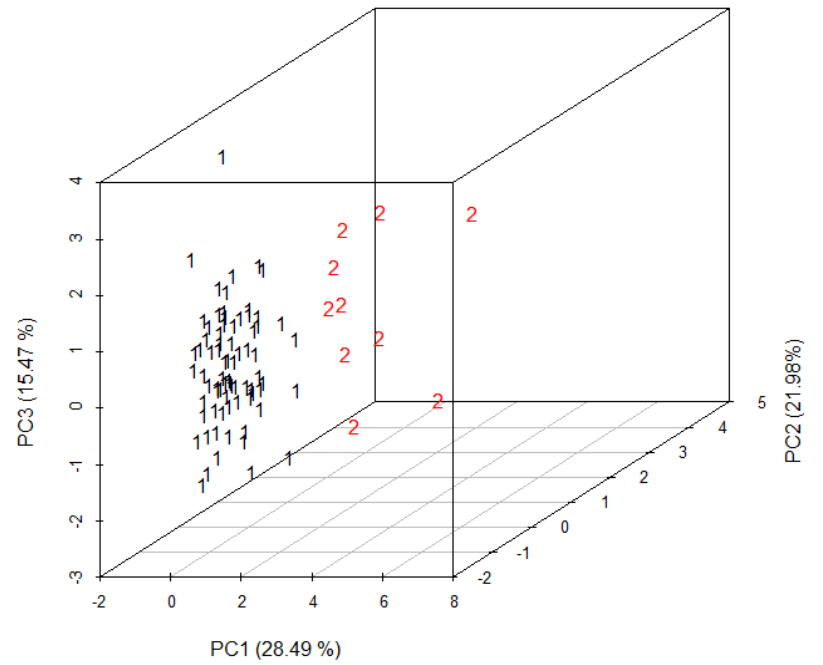

Figure 1: Spatial representation of the hatcheries in the two different clusters (1 and 2) based on the first three principal components.

\begin{tabular}{|c|c|c|}
\hline Variables & Cluster $\mathbf{1} \mathbf{n = 7 5}$ & Cluster $\mathbf{2} \mathbf{~ n = 1 0}$ \\
\hline Average yield per hectare (tonnes) & $10.49^{\mathrm{a}} \pm 0.23$ & $12.30^{\mathrm{b}} \pm 0.41$ \\
\hline $\begin{array}{c}\text { Average feed consumption per hectare } \\
\text { (tonnes) }\end{array}$ & $16.25^{\mathrm{a}} \pm 0.34$ & $19.55^{\mathrm{b}} \pm 0.59$ \\
\hline Average survival during grow-out period (\%) & $84.85^{\mathrm{a}} \pm 0.33$ & $85.25^{\mathrm{a}} \pm 0.95$ \\
\hline Average growth period (months) & $4.95^{\mathrm{a}} \pm 0.06$ & $4.90^{\mathrm{a}} \pm 0.10$ \\
\hline Average input cost per hectare (Lakh) & $3.81^{\mathrm{a}} \pm 0.10$ & $4.52^{\mathrm{a}} \pm 0.40$ \\
\hline Average farm gate price (Taka/kg) & $95.20^{\mathrm{a}} \pm 0.70$ & $98.50^{\mathrm{a}} \pm 2.08$ \\
\hline
\end{tabular}

${ }^{*}$ Lakh $=100,000$ Taka; Means with different superscript letters on the same row are significantly different.

Table 8: The numbers of hatcheries in each cluster $(n)$ and mean \pm standard error of the studied variables associated with the performance of the farms supplied by the hatchery for the different clusters. The upper group of variables are significantly different between clusters, the lower group of variables are not.

in Cluster 1. There were no clear differences between the two clusters of hatcheries in relation to the distribution of educational levels of the owners, strains, source of water, source of feed, spawning methods and disease problems within each cluster. The general description of these variables in section 5.1 applies to both clusters.

The age of the owner, number of eggs per spawning, hatching rate and survival rate from hatching to stocking were excluded from the PCA analysis, but the lack of significant differences between the hatchery groups for these variables suggests no major influence themselves on hatcheries. Additional examination of these variables in relation to others suggested no major differential influence on hatchery performance.

The commercial farms supplied by the hatcheries in Cluster 2 were characterized by high inputs and outputs during the grow-out period. They had significantly higher feed consumption and input cost per hectare and in return had a significantly higher yield per hectare than the farms supplied by hatcheries in Cluster 1 (Table 8).

\section{Discussion}

The current study indicates that the main differences between tilapia hatcheries were in the size of the hatchery, number of staff and facilities for production, associated with large differences in fry production and total annual income among hatcheries. Of the two groups identified in the cluster analysis, the average production of fry in one (Cluster 2) was around three times the average production of fry in the other. The 
hatcheries in Cluster 2 represented $11.76 \%$ of the sampled hatcheries but they produced around $32 \%$ of the total production of fry from all hatcheries in 2009.

The brood stocks of the hatcheries in Cluster 1 were smaller than those in Cluster 2. Brood stock size was the third PCA vector, however, the reproductive performance was very similar across all clusters in terms of number of eggs produced per female per spawning and hatching rate so the difference in size of brood stocks did not appear to have a major effect on egg and fry production per se. The fourth PCA vector was associated with factors potentially linked to the knowledge and experience of the staff and reputation of the hatchery, and the cluster of larger hatcheries (Cluster 2) had significantly longer times since establishment than the smaller. However, while both clusters had similar overall number of trainings per hatchery, the higher number of staff in the larger hatcheries means staff in these attended about a third of the trainings per staff member of the smaller hatcheries. This suggests the more recently established hatcheries in Cluster 1 invested more in staff training presumably to improve the production efficiency of the hatchery.

The fact that the Cluster 2 hatcheries supplied larger numbers of farms may simply be a function of their larger size, although their longer time since establishment could be a factor in establishing a reputation with clients. The limited data on the performance of the farm clientele supplied by the two hatchery groups suggests some additional differences however. The commercial farms supplied by the hatcheries in Cluster 1 had a relatively lower yield per hectare at harvest and these farms used the lower amount of feeds in comparison to the commercial farms of Cluster 2.

The input cost per hectare for the farms in the current study did not include labor cost or the cost of renting the ponds. They reflected mainly the cost of feeding, pond preparation and fertilization, with feed accounting for $50-70 \%$ of the total costs [14]. Although the relatively higher input cost per hectare and yield per hectare for the farms in Cluster 2, the feed conversion rates (average feed consumption per hectare divided by average yield per hectare) for the hatcheries in both clusters were very similar (ranged from 1.55 to 1.59 tonnes of feeds/ tonnes of fish). The average farm gate price per kilo of the fish in Cluster 1 was relatively lower also than for farms supplied by Cluster 2. It could be due to the lower input and feed consumption per hectare of the farms in this cluster which lead to produce smaller fish than the farms in Cluster 2. Smaller fish are normally sold at lower prices than the bigger ones.

The two clusters had some common characteristics. All hatcheries replaced their brood stock every two years from their current brood stock. They had similar timing for fry production with temperatures becoming favorable in February and more suitable during March to May prior to becoming too high for stocking in June and July [15].

GIFT was the main strain of brood stock that hatcheries used in 2009 for the production of fry across the two clusters possibly because of an established reputation for providing good growth. An on-farm trial conducted by BFRI in 1995-1996 indicated that GIFT was, on average, $58 \%$ superior to locally available strains of Nile tilapia in terms of growth [16]. Shortage in supply of brood stocks recorded by Hussain et al. [17] may explain the use of multiple strains in a given hatchery.

The data of the survey showed an increasing trend of the number of new hatcheries established every year since 2001 especially between 2005 and 2009. Nile tilapia continues to increase in popularity in Bangladesh reflecting a continued profitability with respect to other species [6].
In 2014 the number of hatcheries is estimated at 400 producing 3.5 to 4.0 billion fries [5] in comparison to the 191 hatcheries in 2010 that produced 1.4 billion fries [3]. A follow up survey has initiated in 2015 and will continue in 2016 to measure the changes in the production system of mono-sex fry of tilapia in Bangladesh after 2009 [18]

\section{Conclusion}

In conclusion, Bangladesh has become one of the largest producers of Nile tilapia worldwide. The survey results showed that the management of tilapia hatcheries is very similar across the country, and differences in hatchery production were not related to differences in the educational level of owners or staff training, or the improved strains of tilapia used by the hatcheries. The main difference between hatcheries was in the scale of production of fry.

\section{Acknowledgements}

This paper is a contribution to the CGIAR Research Program on Livestock and Fish

\section{References}

1. Bentsen HB, Eknath AE, Palada-De VMS, Danting JC, Bolivar HL, et al. (1998) Genetic improvement of farmed tilapias: Growth performance in a complete diallel cross experiment with eight strains of Oreochromis niloticus. Aquaculture 160: 145-173.

2. FAO (2014) The state of world fisheries and aquaculture. Rome.

3. Anwar J (2011) Market study on some freshwater farmed fish: Tilapia and Pangas. Consultancy report prepared for the PRICE Project.

4. Ponzoni RW, Khaw HL, Yee HY (2010) GIFT: The story since leaving ICLARM (Now known as the World Fish Center of socio-economic, access and benefit sharing and dissemination aspects. Fridtj of Nansens Institute, Lysaker, Norway.

5. Hussain MG, Barman BK, Karim M, Keus EHJ (2014) Green crabs coming to Maryland, The fish site.

6. Belton B, Manjurul K, Thilsted S, Jahan KM, Collis W, et al. (2011) Review of aquaculture and fish consumption in Bangladesh. The World Fish Center.

7. Gale WL, Fitzpatrick MS, Lucero M, Contreras-Sanchez WM, Schreck CB (1999) Masculinization of Nile tilapia (Oreochromis niloticus) by immersion in androgen. Aquaculture 178: 349-357.

8. Field AP (2000) Discovering statistics using SPSS for Windows: Advanced techniques for the beginner. Sage Publications, London.

9. Kaiser HF (1960) The application of electronic computers to factor analysis Educational and Psychological Measurements 20: 141-151.

10. Husson F, Josse J, Pages J (2010) Principal component methods Hierarchical clustering - partitional clustering: Why would we need to choose for visualizing data? Technical Report of the Department of Applied Mathematics (Agrocampus)

11. Rousseeuw PJ (1987) Silhouettes: A graphical aid to the interpretation and validation of cluster analysis. J Comput Appl Math 20: 53-65.

12. SPSS (Statistical Package for the Social Sciences) Inc. (2010) IBM-SPSS Statistics for Windows, Armonk, IBM Corp, NY, USA.

13. Cerny BA, Kaiser HF (1977) A study of a measure of sampling adequacy for factor analytic correlation matrices. Multivar Behav Res 12: 43-47.

14. El-Sayed AFM (2006) Tilapia Culture. CABI Publishing, Wallingford, Oxon, UK

15. Faruk MAR, Mausumi MI, Anka IZ, Hasan MM (2012) Effects of temperature on the egg production and growth of monosex Nile tilapia Oreochromis niloticus fry. Bangladesh Res Pub J 7: 367-377.

16. Hussain MG, Kohinoor AHM, Islam MS, Hossain MA, Dey MM, et al. (2000) Growth and production performances of GIFT strain of Nile tilapia, Oreochromis niloticus L., in ponds and cages under different farming conditions in Bangladesh. J Aqua Trop 15: 273-280.

17. Hussain MG, Barman BK, Karim M, Keus EHJ (2013) Progress and the future for tilapia farming and seed production in Bangladesh, Worldfish.

18. Barman BK (2015) Personal communication on a survey of mono-sex tilapia hatcheries in Bangladesh, Feed Survey. 